\title{
Analisis Keputusan Pembelian Mie Samyang Halal Di Jakarta
}

\author{
Novida Maharani ${ }^{1}$, Tati Handayani ${ }^{2}$, Prima Dwi Priyatno ${ }^{3}$ \\ 1 Universitas Pembangunan Nasional Veteran Jakarta, novida.maharani@upnvj.ac.id \\ 2 Universitas Pembangunan Nasional Veteran Jakarta, tati.handayani@upnvj.ac.id \\ ${ }^{3}$ Universitas Pembangunan Nasional Veteran Jakarta, primadpriyatno@upnoj.ac.id
}

\section{A R T I C L E I N F O}

Article history:

Received : 16/10/2021

Revised : 22/10/2021

Accepted: $26 / 10 / 2021$

Key words:

Halal label, purchase decision, promotion.

DOI:

Doi.org/10.37366/jespb.v6i02.240

\begin{abstract}
A B S T R A C T
This study aims to analyze and prove the effect of halal labels and promotions on purchasing decisions for samyang noodles in Jakarta. The population used in this study is the people of Jakarta. The sampling used was using the Lemeshow formula by determining the unknown population size of 100 respondents. Data analysis techniques to determine the magnitude of the effect of halal labels and promotions on purchasing decisions for samyang noodles are Validity Test, Reliability Test, Classical Assumption Test, and Multiple Linear Regression, $t$-test, f-test, and Coefficient of Determination Test with the help of SPSS 20. The results of this study shows that the halal label has a significant positive effect on purchasing decisions for samyang noodles, and promotions has a significant positive effect on purchasing decisions for samyang noodles. Halal label and promotion together have a significant influence on purchasing decisions for samyang noodles. Research that has been carried out and carried out still has many shortcomings and limitations in its manufacture so that the limitations that limit this research are the "lockdown" conditions imposed during the Covid-19 pandemic which caused various obstacles in data collection, respondents were only taken by region, and time constraints.
\end{abstract}

\section{A B S T R A K}

Penelitian ini bertujuan untuk menganalisis dan membuktikan pengaruh label halal, dan promosi terhadap keputusan pembelian mie samyang di Jakarta. Populasi yang digunakan dalam penelitian ini yaitu Masyarakat Jakarta. Pengambilan sampel yang digunakan yaitu memakai rumus Lemeshow dengan menentukan ukuran populasi yang tidak diketahui sebanyak 100 responden. Teknik analisis data untuk mengetahui besaran pengaruh label halal dan promosi terhadap keputusan pembelian mie samyang adalah Uji Validitas, Uji Reliabilitas, Uji Asumsi Klasik, dan Regresi Linier Berganda, Uji t, Uji f, dan Uji Koefisien Determinasi dengan bantuan SPSS 20. Hasil penelitian ini menunjukan bahwa Label halal memiliki pengaruh positif signifikan terhadap keputusan pembelian mie samyang, dan Promosi memiliki pengaruh yang signifikan positif terhadap keputusan pembelian mie samyang. Label halal dan promosi secara bersama-sama memiliki pengaruh yang signifikan terhadap keputusan pembelian mie samyang. Penelitian yang telah dilaksanakan dan dijalankan masih banyak kekurangan dan keterbatasan dalam pembuatannya sehingga keterbatasan yang membatasi penelitian ini adalah kondisi "lockdown" yang diberlakukan selama pandemic Covid-19 yang menyebabkan berbagai hambatan dalam pengumpulan data, responden yang hanya diambil berdasarkan wilayah saja, dan keterbatasan waktu.

\section{PENDAHULUAN}

Pada masa globalisasi seperti saat ini gaya hidup masyarakat mulai beralih menjadi praktis. Banyak dari kebutuhan masyarakat yang berganti menjadi serba praktis salah satunya merupakan santapan. Fenomena ini membuat industri santapan paling utama di Indonesia menghadapi perkembangan yang lumayan besar serta masih berpotensi untuk berkembang. Perkembangan industri mie terjadi peningkatan yang signifikan terhadap permintaan akan mie instan (Perwitasari, 2021). Mie instan adalah makanan yang disukai oleh semua masyarakat, mie ini dimasak sangat praktis 
cuma dengan merebus mie praktis tersebut didalam panci yang telah berisi air mendidih serta bisa disajikan didalam mangkok sehabis itu ditambahkan bumbu bumbu yang telah berisi didalam kemasan (Purba, 2021).

Masyarakat di Indonesia sudah tidak asing dengan produk mie yang impor dan mie yang terkenal dari korea yaitu Mie Samyang. Mie Samyang yang populer atas viralnya 'Samyang Challenge' beberapa tahun lalu. Buldalk Bokkeummyeon (rasa ayam pedas) adalah nama asli produk mie samyang ini. Samyang food inc ini merupakan nama dari perusahaan yang memproduksi mie terkenal. Semenjak mie samyang tersebar di Indonesia tahun 2015 yang telah memiliki logo halal, akan tetapi logo halalnya masih memakai logo dari Federasi Muslim Korea yang tidak dapat masuk ke Indonesia. Perusahaan mie samyang ini memandang kepedulian warga tentang kehalalan sesuatu produk yang sangatlah berarti (Rahayu, Martha, 2017).Suatu kewajiban jika setiap orang memasukan atau memproduksi pangan ke wilayah Indonesia merupakan keterangan yang ada pada label. Maka, pencantuman keterangan halal pada label pangan bukan merupakan suatu kewajiban untuk semua produsen pangan (Amaliah, Murdiati, 2013).

Industri yang melakukan sesuatu usaha bergerak dibidang santapan serta minuman tidak hendak terlepas dari sertifikat halal, dan tujuannya bisa membagikan kepastian status kehalalan suatu produk. Agar masyarakat bisa mengidentifikasi mie samyang yang hendak dimakan serta status dari kehalalan produk tersebut. Pastinya pada produk makanan tersebut mencantumkan label yaitu menandai atau sebagai logo gambar halal ataupun tidak halal. Label ini jadi aksesoris selaku data untuk konsumen dari benda yang mau dibelinya, saat sebelum membeli umumnya masyarakat bisa membaca informasi yang tercantum pada label produk tersebut. Sebagai regulator produk halal di Indonesia, Sertifikat ini diperoleh melewati segala proses pengujian yang ketat sehingga memenuhi persyaratan halal yang diresmikan oleh LPPOM MUI. Kemudian Mie Samyang sudah mengantongi sertifikat halal dari Federasi Muslim Korea serta ijin edar dari Tubuh Pengawas Obat serta Santapan Republik Indonesia (BPOM RI) (LPPOM, 2021).

Dalam QS Al-Baqarah ayat 168 menjelaskan Tentang Makanan Halal:

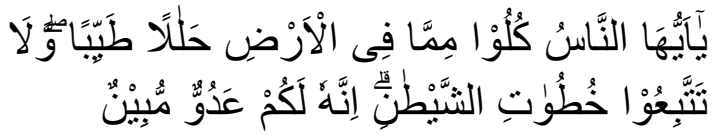

Wahai manusia, makanlah sebagian (makanan) di bumi yang halal lagi baik dan janganlah mengikuti langkah-langkah setan. Sesungguhnya ia bagimu merupakan musuh yang nyata.

Masyarakat masih kurang aware dengan label halal yang tercantum pada kemasan produk tersebut buat membagikan awareness yang baik untuk para konsumen setia serta masyarakat Jakarta, samyang green ini menggelar samyang Challenge (Suteja, 2021). PT Jakarta Boga Utama Sari Dalam berpromosi meluncurkan Samyang terkini ialah Hot Chicken Flavor Ramen Stew Type, Ramen Spicy, Hot Chicken Flavor Ramen Jjajang, serta Buldak Sauce. Melalui promo challenge ini, optimis varian terkini Samyang setidaknya bisa memacu perkembangan bisnis sebesar 10 persen di tahun ini (Aisyah, 2021).

Mie Samyang Green yang telah bersertifikat halal. Sejak lama Mie Samyang Green ini sudah dikenal Ketetapan Halal MUI sudah dimiliki dari memasuki pasar Indonesia. Produk impor yang sudah bersertifikat halal dan menciptakan izin edar merupakan Samyang Green. Ketetapan Halal MUI menjadi suatu Keunggulan utama dari produk. Produk yang dipasarkan di Indonesia memenuhi hak konsumen nyatanya, dengan adanya Ketetapan Halal MUI menjadi salah satu produk terjamin halal yang sudah dibuktikan. Ada sebagian kualitas yang sama dengan opsi produk, konsumen muslim hendak lebih memilah produk berlogo halal MUI dan memberikan nilai tambah yang besar terhadap penjualan produk. Suatu produk impor yang rasanya bisa diterima oleh kebanyakan lidah masyarakat Indonesia merupakan Samyang Green (LPPOM, 2021).

Pada penjelasan yang telah dijelaskan maka dapat dirumuskan masalah dalam penelitian ini, yaitu Apakah terdapat pengaruh label halal, 
promosi serta label halal dan promosi mie samyang secara bersama-sama terhadap keputusan pembelian masyarakat Jakarta?

\section{Tujuan Penelitian}

Untuk menganalisis dan membuktikan pengaruh label halal, promosi serta label halal dan promosi mie samyang terhadap keputusan pembelian masyarakat Jakarta.

\section{Manfaat Penelitian}

Pertama, secara teoritis untuk menambah wawasan pembaca mengenai Label Halal dan Promosi mie samyang terhadap keputusan pembelian masyarakat Jakarta dan untuk membantu penelitian-penelitian selanjutnya. Kedua, secara praktis untuk referensi mengenai Apakah pengaruh Label Halal dan Promosi mie Samyang terdahap keputusan pembelian masyarakat Jakarta dan untuk perusahaan dapat memperkuat pemasaran agar meningkatkan penjualan.

\section{TINJAUAN PUSTAKA}

\section{Keputusan Pembelian}

Menurut Tjiptono (2016) mendefinisikan salah satu bagian dari perilaku konsumen merupakan keputusan pembelian. Perilaku konsumen adalah Sebuah tindakan yang langsung dan terlibat dalam menentukan produk dan jasa,usaha memperoleh, dan sebuah proses pengambilan keputusan yang mengikuti tindakan dan mendahului (Tjiptono, 2016).

Menurut Kotler \& Amstrong (2016) Keputusan Pembelian yaitu bagian dari perilaku konsumen, tentang bagaimana organisasi, kelompok, dan individu melakukan proses membeli, menggunakan, memilih dan memastikan bahwa barang atau jasa memenuhi kebutuhan mereka (Kotler \& Armstrong, 2016).

Bagi Kotler dan Keller (2012) Proses dimana konsumen melewati lima sesi, yaitu pencarian informasi, pengenalan permasalahan, keputusan pembelian, penilaian alternatif merupakan suatu proses keputusan pembelian, sertasikap pasca pembelian, yang diawali jauh saat sebelum pembelian aktual dicoba dan memiliki akibat yang lama sehabis itu (Kotler \& Keller, 2012).

\section{Label Halal}

Bagi maimunah pulungan hindun, et,al Label merupakan tulisan, keterangan yang berupa gambar, atau deskripsi lain yang tertulis maupun dicetak, dicantumkan serta menempel kemasan produk (Pulungan, Hindun et al., 2018).

Label ialah tiap penjelasan menimpa pangan olahan yang berupa foto, tulisan, campuran keduanya, ataupun wujud lain yang disertakan pada pangan olahan, dimasukan ke dalam, ditempelkan pada, ataupun ialah bagian kemasan pangan (BPOM, 2020).

Halal berasal dari bahasa Arab (halla-yahilluhillan) yang memiliki makna memperbolehkan, membubarkan, memlepaskan, melepaskan, dan membongkar. Bila memakainya memperoleh makna sesuatu yang menjadikan seorang leluasa, lepas dari hukuman. Dengan kata lain diperbolehkan bagi hukum Islam, yakni Mengenai yang diperlukan dalam komsumsi benda serta jasa untuk seseorang muslim. Halal yakni segala objek ataupun kegiatan yang diperbolehkan serta diizinkan buat digunakan ataupun dilaksanakan dalam agama Islam. Sebutan ini dalam kata tiap hari lebih kerap digunakan buat menampilkan minuman serta santapan yang diizinkan buat disantap bagi syariat Islam tercantum tipe serta metode memperolehnya. Dengan kata lain, style hidup halal berarti pola hidup seorang ataupun perilaku dalam aktivitas tiap hari mengawali kegiatan, atensi, serta opini yang cocok dengan prinsip syariah bersumber pada Qur'an serta Hadits (Yetti \& Priyatno, 2021).

\section{Promosi}

Bagi Freddy Rangkuti (2013) promosi yakni suatu aktivitas industri yang memberitahukan arus data supaya konsumen terus mengingatnya sehingga mencuat kemauan konsumen buat berupaya serta membeli produk industri (Rangkuti, 2013).

Promosi ialah aktivitas industri yang dirancang buat mempengaruhi pelanggan sehingga mereka dapat menguasai produk yang diberikan industri 
kepada mereka, dan sehabis itu jadi tertarik dengan produk dan membelinya, tujuan dikerjakannya promosi merupakan buat menjual segala sesuatu yang mau diperjualbelikan pada konsumen. Suatu upaya yang dicoba salah satunya dengan memakai konsep serta prinsip marketing buat memasarkan sesuatu produk ataupun jasa yang dimiliki yakni promosi (Halim, 2013).

Dalam sesuatu hadist disebutkan Ibnu Umar Berkata 'Seorang pria mengadu pada Nabi, Aku telah tertipu dalam jual beli. Sampai ia bersabda, katakanlah kepada orang yang kamu ajak berjual beli, tidak boleh menipu!. Sejak itu, apabila ia bertransaksi jual beli, ia mengatakanya' (HR Bukhari).

Promosi ialah sebagai sarana yang digunakan industri buat membujuk, menginformasikan, serta menegaskan konsumen langsung ataupun tidak langsung tentang merk yang mereka jual serta produk tersebut. lewat periklanan ialah salah satu melakukan promosi (Agustin, 2019).

\section{Model Penelitian}

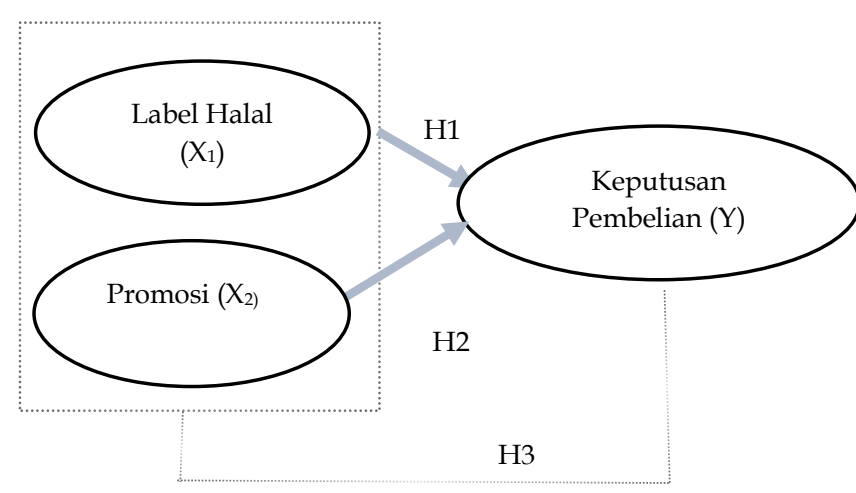

\section{Hipotesis}

H1: Diduga terdapat pengaruh Label Halal Mie Samyang terhadap keputusan pembelian.

H2: Diduga terdapat pengaruh Promosi Mie Samyang terhadap keputusan pembelian.

H3: Diduga terdapat pengaruh label halal dan Promosi Mie Samyang terhadap keputusan pembelian.

\section{METODOLOGI PENELITIAN}

Penelitian ini ialah penelitian yang berjenis penelitian kuantitatif. Populasi yang digunakan dalam penelitian ini yaitu Masyarakat Jakarta. Pengambilan sampel yang digunakan yakni memakai rumus lemeshow dengan menentukan ukuran populasi yang tidak diketahui. Maka jumlah sampel yang digunakan memakai rumus lemeshow yaitu 100 orang. Menurut (Sugiyono, 2014) Data primer merupakan data yang diperoleh langsung dari responden penelitian dengan memakai alat pengukuran berbentuk kuesioner untuk memperoleh informasi tersebut. Adapun sumber data primer yang digunakan dalam penelitian ini dan didapat dari responden masyarakat Jakata. Teknik analisis data yang digunakan dalam penelitian ini, yaitu menggunakan uji validitas, uji reliabilitas, dan uji asumsi klasik, serta uji regresi linier berganda dengan menggunakan bantuan SPSS versi 20. Variabel yang digunakan dalam penelitian ini yaitu Keputusan Pembelian sebagai variabel terikat Y. Kemudian untuk variabel bebasnya Label Halal sebagai variabel (X1), dan Promosi sebagai variabel $(\mathrm{X} 2)$.

\section{HASIL DAN PEMBAHASAN}

Samyang adalah nama dari perusahaan yang memproduksi mie yang terkenal pedas yaitu samyang Foods Inc. PT Korinus ini telah mengimpor dan memiliki label halal. pada 15 september 1961 Samyang Food didirikan oleh Jeon Jung Yoon, di tahun 1963 mie samyang merintis sebagai mie instan korea pertama diawal tahun 1970-an. Dan pada 1980 Samyang Food memproduksi berbagai macam produk makanan ringan, susu, dan saus. Samyang food akan mengekspor dan meningkatkan produk sehingga mendapatkan keuntungan perusahaan. Pada 2014 Samyang Foods juga telah memperoleh sertifikat halal internasional.

\section{Deskripsi Data Penelitian}

Peneliti melakukan sebaran kuesioner kepada 100 responden melalui google form.

\section{a) Karakteristik responden}

Deskripsi Data dan Responden dilihat di Tabel 2 mendeskripsikan data responden menurut jenis kelaminnya:

Tabel 2. Karakteristik responden

\begin{tabular}{lll}
\hline Jenis Kelamin & Frekuensi & Presentase \\
\hline Perempuan & 70 & $70 \%$ \\
\hline Laki-Laki & 30 & $30 \%$ \\
\hline & Jumlah & $100 \%$
\end{tabular}

Sumber: data diolah dengan excel, (2021) 
Maka dari itu dapat disimpulkan jumlah responden perempuan mendominasi dalam pengisian kuesioner ini dibandingkan laki laki.

\section{b) Berdasarkan umur}

Dibawah ini adalah Tabel 3 tampilan umur responden:

Tabel 3. Umur Responden

\begin{tabular}{llll}
\hline No & Usia & Frekuensi & Presentase \\
\hline 1 & $18-25$ & 72 & $72 \%$ \\
\hline 2 & 26 tahun keatas & 28 & $28 \%$ \\
\hline & & Jumlah & $100 \%$ \\
\hline
\end{tabular}

Sumber: data diolah dengan excel, (2021)

Maka dari itu dapat disimpulkan bahwa kategori usia 18-25 mendominasi sebesar 72\% dari jumlah responden.

\section{c) Berdasarkan Wilayah}

Dibawah ini dapat dilihat karakeristik responden berdasarkan wilayah:

\begin{tabular}{lllc}
\hline No & Wilayah & Frekuensi & Presentase \\
\hline 1 & Jakarta Barat & 40 & $40 \%$ \\
\hline 2 & Jakarta Timur & 15 & $15 \%$ \\
\hline 3 & Jakarta Selatan & 22 & $22 \%$ \\
\hline 4 & Jakarta Utara & 16 & $16 \%$ \\
\hline 5 & Jakarta Pusat & 7 & $7 \%$ \\
\hline & & Jumlah & $100 \%$ \\
\hline
\end{tabular}

Tabel 4. Wilayah Responden

Sumber: data diolah dengan excel, (2021)

Maka dari itu dapat disimpulkan wilayah responden didominasi oleh responden yang berwilayah dijakarta barat dengan jumlah responden 40 orang atau $40 \%$ dari total 100 responden.

\section{Analisis Data Deskriptif}

Menurut (Riyanto. \& Hatmawan., 2020) analisis deskriptif merupakan analisis yang dilakukan untuk menilai sesuatu ciri dari sebuah data yang diteliti. Dilihat dari hasil rata rata Tabel 5 mengenai Tanggapan Kuesioner Keputusan Pembelian:

Tabel 5. Tanggapan Kuesioner Keputusan Pembelian $(\mathrm{Y})$

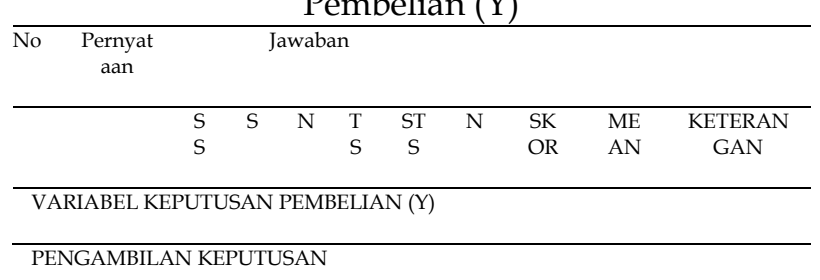

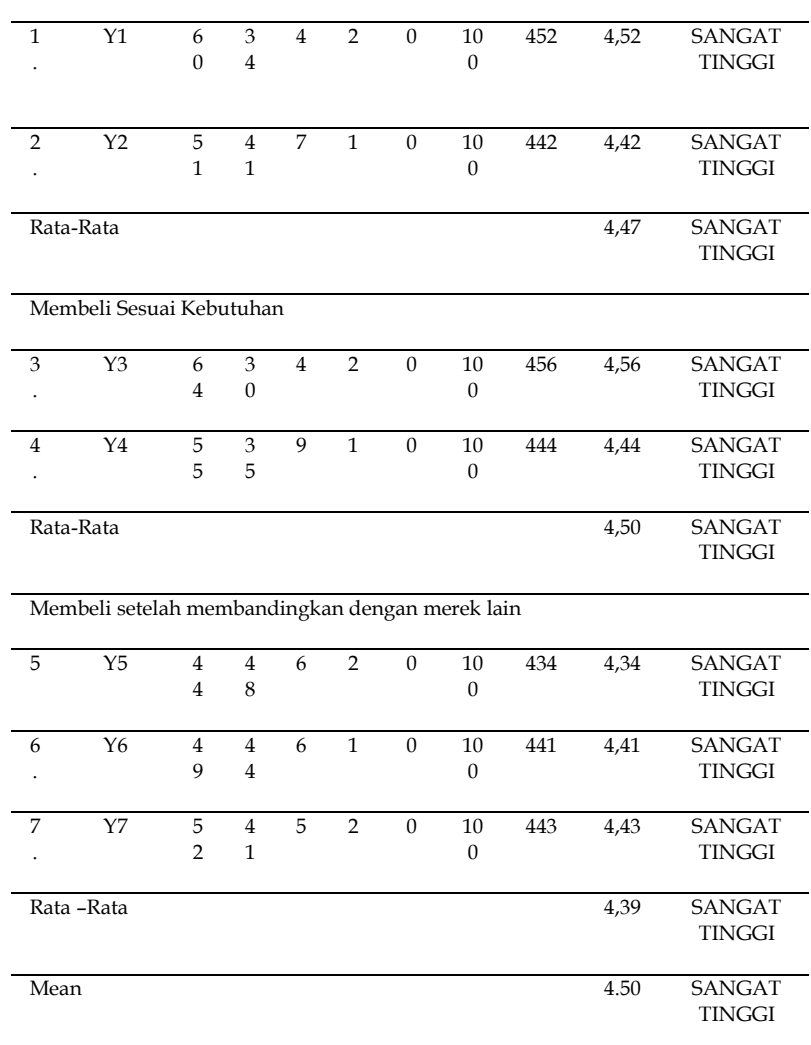

Sumber: Tanggapan Kuesioner $\mathrm{Y}$ data diolah dengan excel, (2021)

Dari data diatas dapat disimpulkan bahwa secara total dari ketiga indikator variabel keputusan pembelian menghasilkan akumulasi rata rata skor sebesar 4,50. Hasil pada tabel diatas masuk pada skala interval 4,20 - 5,00. Oleh karena ini disimpulkan secara keseluruan keputusan pembelian mie samyang termasuk dalam kategori sangat tinggi, karena masyarakat membeli produk mie samyang yang sudah memiliki label halal dan memenuhi syariat islam sehingga masyarakat merasa aman untuk mengkonsumsi mie samyang yang sudah berlabel halal, dan sudah teruji kehalalannya oleh MUI, serta dari rasa mie samyang memiliki rasa yang berbeda dari mie instan yang lain.

Selanjutnya dilihat dari hasil rata rata Tabel 6 mengenai tanggapan kuesioner Label Halal: $(\mathrm{X} 1)$

Tabel 6. Tanggapan Kuesioner Label Halal

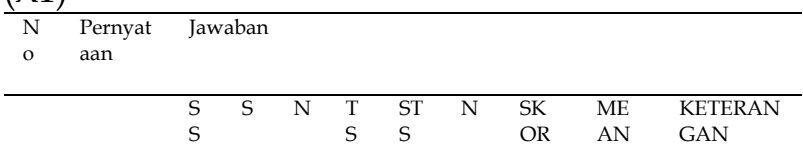

VARIABEL LABEL HALAL (X1) 


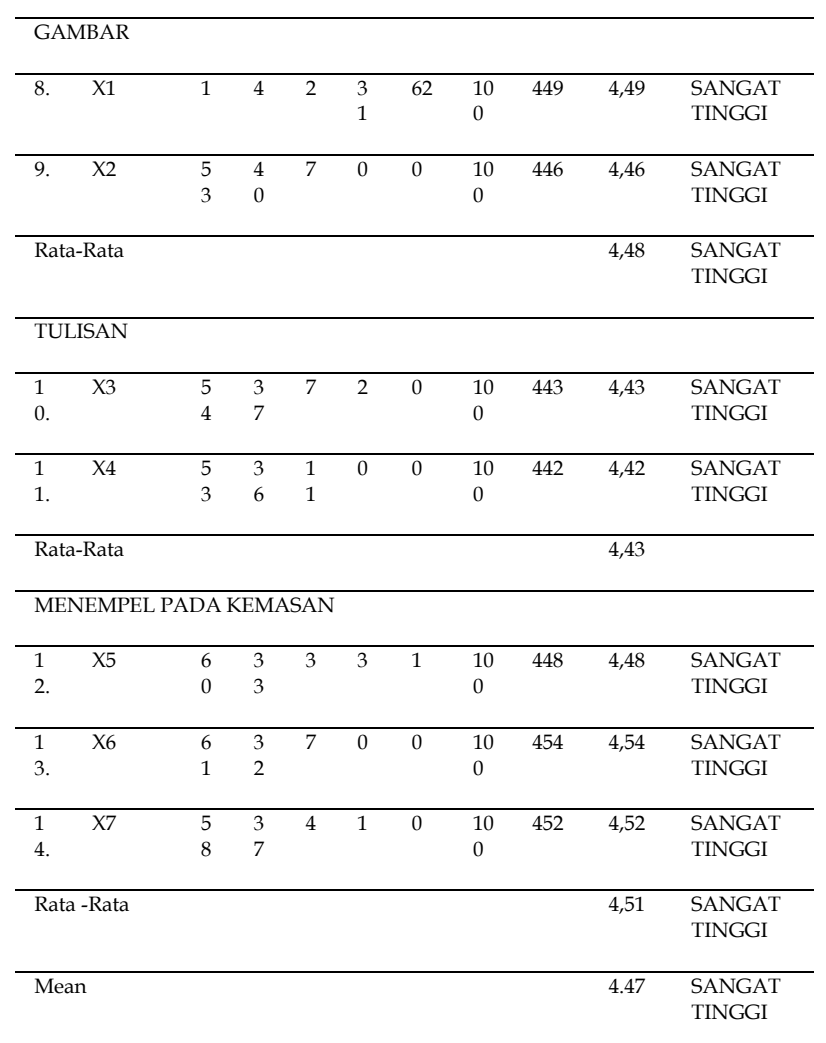

Sumber: Tanggapan Kuesioner diolah dengan excel, (2021)

Dalam data tersebut bisa disimpulkan bahwa secara total dari ketiga indikator variabel label halal menghasilkan akumulasi rata-rata skor sebesar 4,47. Hasil pada rata rata skor diatas masuk pada skala interval 4,20-5,00. Oleh karena itu dapat disimpulkan bahwa secara keseluruhan label halal yang terdapat di kemasan mie samyang di Jakarta termasuk dalam kategori sangat tinggi, karena masyarakat memperhatikan gambar dan tulisan label halal yang dibuat oleh LPPOM MUI pada kemasan yang memperkuat bahwa mie samyang halal.
Selanjutnya dilihat dari hasil rata rata Tabel 7 mengenai Tanggapan kuesioner Promosi:

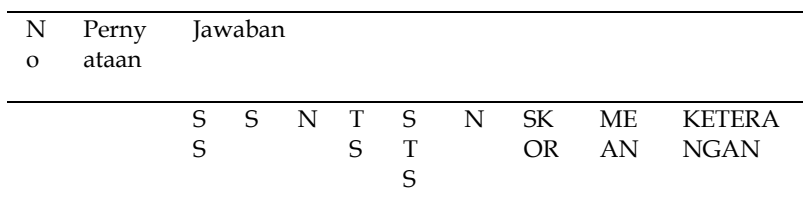

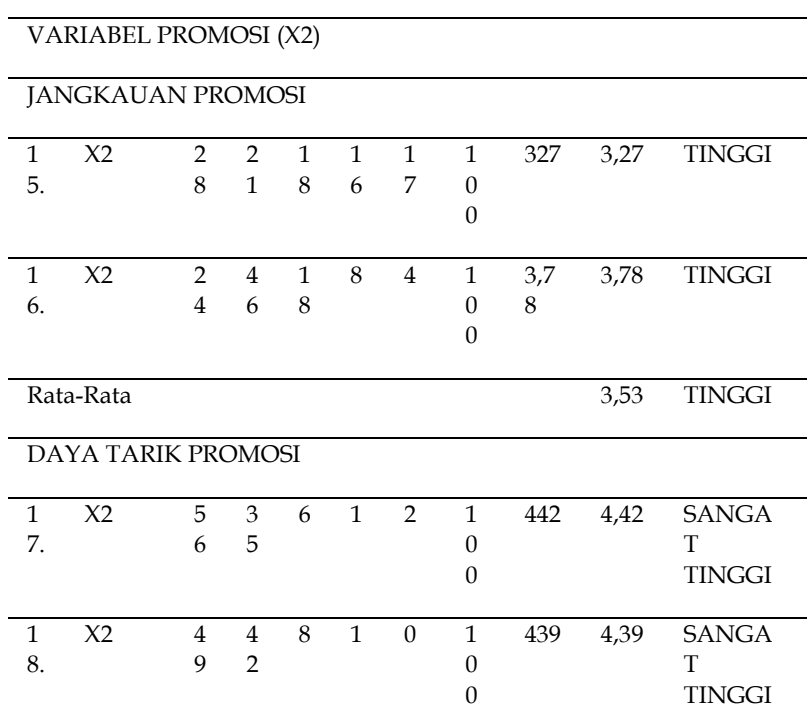

\begin{tabular}{lllllllllll}
\hline 1 & $\mathrm{X} 2$ & 3 & 2 & 2 & 1 & 4 & 1 & 373 & 3,73 & TINGGI \\
9. & & 5 & 5 & 2 & 4 & & 0 & & & \\
& & & & & & & 0 & & &
\end{tabular}

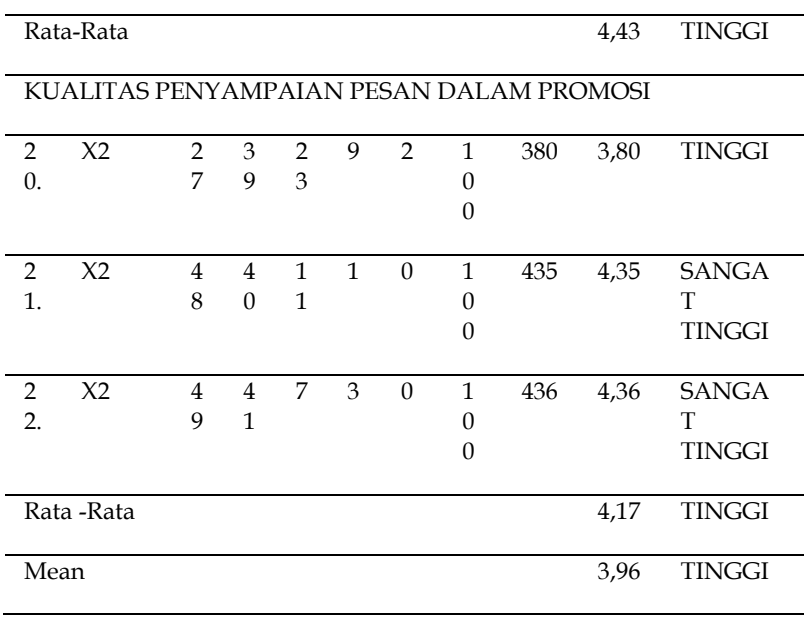

Tabel 7. Tanggapan Kuesioner Promosi (X2)

Sumber: Tanggapan Kuesioner diolah oleh excel, (2021)

Dalam data tersebut bisa disimpulkan bahwa secara total dari ketiga indikator variabel promosi menghasilkan akumulasi rata-rata skor sebesar 3,96. Hasil pada tabel diatas masuk pada skala interval 3,40-4,19. Oleh karena itu dapat disimpulkan bahwa secara keseluruhan promosi yang terdapat di kemasan mie samyang di Jakarta termasuk dalam 
kategori tinggi, karena dengan promosi yang dilakukan oleh media sosial membuat masyarakat tertarik pada mie samyang sehingga membuat masyarakat menghilangkan rasa lapar,dan membuat sensasi pedas yang berbeda dari mie instan yang lain.

\section{Uji Validitas}

Uji Validitas ialah tingkatan ketelitian antara data yang terjadi pada objek penelitian dengan data yang dapat dilaporkan oleh peneliti (Sugiyono, 2015).

Hasil uji validitasnya dilihat dari Tabel 8 Uji Validitas Label Halal:

Tabel 8. Uji Validitas Label Halal (X1)

\begin{tabular}{ccccc}
\hline Pernyataan & Rhitung & Tanda & Rtabel & Keterangan \\
\hline Pernyataan 1 & 0,719 & $>$ & 0,196 & valid \\
\hline Pernyataan 2 & 0,768 & $>$ & 0,196 & Valid \\
\hline Pernyataan 3 & 0,846 & $>$ & 0,196 & Valid \\
\hline Pernyataan 4 & 0,759 & $>$ & 0,196 & Valid \\
\hline Pernyataan 5 & 0,809 & $>$ & 0,196 & Valid \\
\hline Pernyataan 6 & 0,709 & $>$ & 0,196 & Valid \\
\hline Pernyataan 7 & 0,797 & $>$ & 0,196 & Valid \\
\hline
\end{tabular}

Sumber: data diolah dengan spss 20, (2021)

Pada data diatas dilihat bahwa semua nilai Rhitung $>$ Rtabel $(0,196)$ dari semua pernyataan indikator dalam label halal dapat diambil kesimpulan bahwa semua pernyataan adalah valid, dan semua pernyataan dapat dilakukan dalam model pengujian.

Selanjutnya dibawah ini menunjukan Tabel 9 mengenai hasil Uji Validitas Promosi:

Tabel 9. Uji Validitas Promosi (X2)

\begin{tabular}{ccccc}
\hline Pernyataan & Rhitung & Tanda & Rtabel & Keterangan \\
\hline Pernyataan 1 & 0,689 & $>$ & 0,196 & Valid \\
\hline Pernyataan 2 & 0,779 & $>$ & 0,196 & Valid \\
\hline Pernyataan 3 & 0,567 & $>$ & 0,196 & valid \\
\hline Pernyataan 4 & 0,488 & $>$ & 0,196 & Valid \\
\hline Pernyataan 5 & 0,789 & $>$ & 0,196 & Valid \\
\hline Pernyataan 6 & 0,841 & $>$ & 0,196 & Valid \\
\hline Pernyataan 7 & 0,737 & $>$ & 0,196 & Valid \\
\hline Pernyataan 8 & 0,629 & $>$ & 0,196 & Valid
\end{tabular}

Sumber: data diolah dengan spss 20, (2021)

Pada data diatas dilihat dari keseluruhan nilai Rhitung > Rtabel 0,196 dan dapat diambil kesimpulan bahwa semua pernyataan setiap indikator dalam promosi merupakan valid, semua pernyataan dapat dilakukan dalam model pengujian.
Selanjutnya dibawah ini Tabel 10 menunjukan hasil Uji Validitas Keputusan Pembelian:

Tabel 10. Uji Validitas Keputusan Pembelian (Y)

\begin{tabular}{ccccc}
\hline Pernyataan & Rhitung & Tanda & Rtabel & Keterangan \\
\hline Pernyataan 1 & 0,732 & $>$ & 0,196 & Valid \\
\hline Pernyataan 2 & 0,770 & $>$ & 0,196 & Valid \\
\hline Pernyataan 3 & 0,788 & $>$ & 0,196 & Valid \\
\hline Pernyataan 4 & 0,695 & $>$ & 0,196 & Valid \\
\hline Pernyataan 5 & 0,586 & $>$ & 0,196 & Valid \\
\hline Pernyataan 6 & 0,549 & $>$ & 0,196 & valid \\
\hline Pernyataan 7 & 0,707 & $>$ & 0,196 & Valid \\
\hline
\end{tabular}

Sumber: data diolah dengan spss 20, (2021)

Pada data yang ada pada tabel 10 dari semua keseluruhan nilai Rhitung > Rtabel 0,196 dan dapat diambil kesimpulan bahwa dari semua pernyataan indikator dalam keputusan pembelian adalah valid, semua pertanyaan dapat dilakukan dalam model pengujian.

\section{Uji Reliabilitas}

Menurut (Ghozali, 2012), reabilitas adalah seberapa tingkat handal kuesioner peneliti. Dapat dilihat dari Tabel 11 mengenai hasil Uji Reliabilitas Label Halal, Promosi, dan Keputusan Pembelian:

Tabel 11. Uji Reliabilitas

\begin{tabular}{ccccc}
\hline Variabel & $\begin{array}{c}\text { Cronbach } \\
\text { Alpha }\end{array}$ & Tanda & $\begin{array}{c}\text { Nilai } \\
\text { Kritis }\end{array}$ & Keputusan \\
\hline Label Halal & 0,885 & $>$ & 0,60 & Reliabel \\
\hline Promosi & 0,835 & $>$ & 0,60 & Reliabel \\
\hline $\begin{array}{c}\text { Keputusan } \\
\text { Pembelian }\end{array}$ & 0,816 & $>$ & 0,60 & Reliabel \\
\hline
\end{tabular}

Sumber: data diolah dengan spss 20, (2021)

Pada data tabel diatas, dapat dilihat bahwa dari masing- masing variabel label halal, promosi, dan keputusan pembelian memiliki Cronbach alpha > 0,60. Dapat disimpulkan dari data diatas hasil uji reliabilitas terhadap keseluruhan variabel adalah reliabel, sehingga pernyataan diaatas dapat digunakan untuk penelitian selanjutnya.

\section{Uji Asumsi Klasik}

Uji Asumsi Klasik terdiri dari:

a) Uji Normalitas dari hasil penelitian ini terlihat pd gambar ini bahwa apabila titik tersebar disekitar garis diagonal serta menjajaki arah garis diagonal, sehingga dapat disimpulkan bahwa model regresi memenuhi asumsi normalitas. 


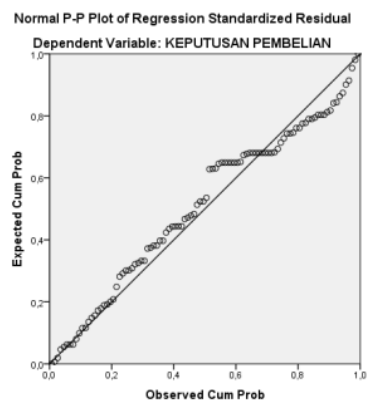

Gambar 1. Uji P Plot

Sumber: data diolah oleh SPSS 20 (2021)

b) Uji Heteroskedastisitas dari hasil penelitian ini terlihat pada Tabel 11 bahwa Jika nilai signifikansi > 0,05 maka data tidak terjadi masalah heteroskedastisitas. Bila varian dari satu residual pengamatan ke pengamatan yang lain tetap, maka disebut homoskadastisitas serta apabila berbeda disebut heteroskedastisistas.

\begin{tabular}{|c|c|c|c|c|c|}
\hline Model & $\begin{array}{c}\text { Unstandardi } \\
\text { ze } \\
\text { B }\end{array}$ & $\begin{array}{c}\text { Coeddicie } \\
\text { nts }\end{array}$ & $\begin{array}{l}\text { Standardi } \\
\text { zed } \\
\text { Coefficien } \\
\text { ts }\end{array}$ & $\mathrm{T}$ & Sig \\
\hline & & & Beta & & \\
\hline 1 (constan & 3,513 & 1.031 & & $\begin{array}{c}3.40 \\
9\end{array}$ & $\begin{array}{c}00 \\
1\end{array}$ \\
\hline $\begin{array}{l}\text { LABEL } \\
\text { HALAL }\end{array}$ &,- 045 & 0,42 &,- 136 & $\begin{array}{c}- \\
1,06 \\
0\end{array}$ & $\begin{array}{c}29 \\
29\end{array}$ \\
\hline PROMOS &,- 021 & 0,29 &,- 093 & $\begin{array}{c}- \\
, 726\end{array}$ & $\begin{array}{c}47 \\
0\end{array}$ \\
\hline
\end{tabular}

Tabel 11. Uji Heteroskedastisitas

Sumber: data diolah dengan SPSS 20, (2021)

Berdasarkan data di atas menunjukan jika nilai signifikansi label halal $(0,292)$ dan promosi $(0,470)>$ 0,05 maka data tidak terjadi heteroskedasistas.

c) Uji Multikolinearitas dari hasil penelitian ini terlihat pada Tabel 12 bahwa Jika nilai Tolerance lebih besar dari 0,10 maka artinya tidak terjadi multikolinieritas dalam model regresi.

Tabel 12. Uji Multikolinearitas

\begin{tabular}{|c|c|c|c|c|c|c|c|}
\hline \multirow[t]{3}{*}{ Model } & \multirow[t]{2}{*}{$\begin{array}{l}\text { Unstand } \\
\text { ardized }\end{array}$} & \multirow[t]{2}{*}{$\begin{array}{l}\text { Coeffi } \\
\text { cients }\end{array}$} & \multirow{2}{*}{$\begin{array}{c}\text { Standa } \\
\text { rdized } \\
\text { coeffici } \\
\text { ents }\end{array}$} & \multirow[t]{3}{*}{$t$} & \multirow[t]{3}{*}{ Sig } & \multirow{3}{*}{$\begin{array}{c}\begin{array}{c}\text { Coline } \\
\text { arity }\end{array} \\
\begin{array}{c}\text { Tolera } \\
\text { nce }\end{array}\end{array}$} & \multirow{3}{*}{$\begin{array}{r}\begin{array}{r}\text { Stati } \\
\text { stic }\end{array} \\
\text { VIF }\end{array}$} \\
\hline & & & & & & & \\
\hline & B & $\begin{array}{l}\text { Std.Er } \\
\text { ror }\end{array}$ & Beta & & & & \\
\hline $\begin{array}{c}1 \\
\text { (consta } \\
n t)\end{array}$ & 8,833 & $\begin{array}{c}1.61 \\
9\end{array}$ & & $\begin{array}{c}5 . \\
45 \\
6 \\
\end{array}$ & $\begin{array}{l}.0 \\
00\end{array}$ & & \\
\hline $\begin{array}{l}\text { LABEL } \\
\text { HALAl }\end{array}$ & 612 & 0,66 & 710 & $\begin{array}{c}9, \\
33 \\
0 \\
\end{array}$ & $\begin{array}{l}.0 \\
00\end{array}$ & .596 & $\begin{array}{c}1,67 \\
9\end{array}$ \\
\hline
\end{tabular}

\begin{tabular}{cccccccc}
\hline PROM & 0,92 & .046 & .152 & 1. & .0 & .596 & 1,67 \\
O & & & & 99 & 49 & & 9 \\
SI & & & & 3 & & & \\
\hline
\end{tabular}

a.dependent Variabel: KEPUTUSAN PEMBELIAN

Sumber: data diolah oleh SPSS 20 (2021)

Pada data diatas menunjukan bahwa ada variabel yang memiliki nilai tolerance kurang 0,10 dan tidak ada yang nilai VIFnya yang lebih dari 10 sehingga dapat disimpulkan bahwa model regresi dalam penelitian ini tidak mengandung multikolinearitas.

\section{Regresi Linear Berganda}

Bagi (Sugiyono, 2015, hlm. 277) Uji regresi linier berganda digunakan untuk meramalkan apabila keadaan naik ataupun turunnya variabel dependen. Pengujian regresi linier berganda menggunakan ketentuan minimal variabel independennya ada 2. Dilihat dari Tabel 13 menunjukan Regresi Linier Berganda:

\begin{tabular}{cccccccc}
\hline Mode & $\begin{array}{c}\text { Unstandar } \\
\text { dized }\end{array}$ & $\begin{array}{c}\text { Coeffi } \\
\text { cients }\end{array}$ & $\begin{array}{c}\text { Standa } \\
\text { rdized } \\
\text { Coeffic } \\
\text { ients }\end{array}$ & T & Sig & $\begin{array}{c}\text { Collon } \\
\text { earity }\end{array}$ & $\begin{array}{c}\text { stati } \\
\text { stics }\end{array}$ \\
\hline & B & $\begin{array}{c}\text { Std.err } \\
\text { or }\end{array}$ & Beta & & & $\begin{array}{c}\text { Tolera } \\
\text { nce }\end{array}$ & VIF \\
\hline $\begin{array}{c}1 \\
\text { const } c\end{array}$ & 8,833 & 1,619 & & 5,456 &, $00 C$ & & \\
\hline LABE &, 617 &, 066 &, 710 & $9,33($ & $0,0 C$ &, 596 & 1,67 \\
HALA & & & & & & & 9
\end{tabular}

\begin{tabular}{|c|c|c|c|c|c|c|c|}
\hline $\begin{array}{c}\text { PROM } \\
\text { SI }\end{array}$ & ,092 & ,046 & 152 & $1,99:$ & $0,4 \mathrm{C}$ & ,59 & $\begin{array}{c}1,67 \\
9\end{array}$ \\
\hline
\end{tabular}

Tabel 13. Regresi Linier Berganda

Sumber: data diolah oleh SPSS 20 (2021)

$\mathrm{Y}=\mathrm{a}+\mathrm{b} 1 \mathrm{X} 1+\mathrm{b} 2 \mathrm{X} 2+\mathrm{e}$

$=8,833+(0,710$ Label Halal $)+(0,152$ Promosi $)$

1) Nilai A 8,833 Merupakan Konstanta atau keadaan variabel keputusan pembelian belum dipengaruhi oleh variabel lain yaitu variabel label halal dan promosi, jika variabel independen tidak ada maka variabel keputusan pembelian tidak mengalami perubahan.

2) B1/X1Nilai Koefisiensi Regresi Label halal sebesar 0,710, yang menunjukan bahwa variabel label halal mempunyai pengaruh yang positif terhadap keputusan pembelian yang berarti bahwa setiap kenaikan 1 satuan variabel label halal maka akan mempengaruhi keputusan 
pembelian sebesar 0,710 dengan asumsi bahwa variabel lain tidak diteliti dalam penelitian ini.

3) B2/X2Nilai Koefiensi Regresi Promosi sebesar 0,152 menunjukan bahwa variabel promosi mempunyai pengaruh yang positif terhadap keputusan pembelian yang berarti bahwa setiap kenaikan 1 satuan variabel promosi maka akan mempengaruhi keputusan pembelian sebesar 0,152 dengan asumsi bahwa variabel lain tidak diteliti dalam peneliti.

\section{Uji Hipotesis Parsial (Uji t)}

Uji Hipotesisi Parsial (Uji t) hasil penelitian ini dilihat dari Tabel 14 bahwa apabila signifikansi < 0,05 maka H0 di tolak serta Ha diterima sehinga dapat diambil kesimpulan bila secara parsial variabel independen mempengaruhi positif signifikan terhadap variabel dependen.

\begin{tabular}{|c|c|c|c|c|c|c|c|}
\hline \multirow[t]{2}{*}{ Model } & $\begin{array}{l}\text { Unstandar } \\
\text { tdized }\end{array}$ & $\begin{array}{c}\text { Standar } \\
\text { dized }\end{array}$ & $\mathrm{T}$ & & Sig & \multicolumn{2}{|c|}{$\begin{array}{l}\text { Collinearity } \\
\text { Statistics }\end{array}$} \\
\hline & B & $\begin{array}{r}\text { Std. } \\
\text { error }\end{array}$ & $\begin{array}{c}\text { Bet } \\
\text { a }\end{array}$ & & & $\begin{array}{l}\text { Toleran } \\
\text { ce }\end{array}$ & VIF \\
\hline $\begin{array}{c}1 \\
\text { (con } \\
\text { stan } \\
\mathrm{t} \text { ) }\end{array}$ & $\begin{array}{r}8 \\
8 \\
3 \\
3 \\
\end{array}$ & 1,619 & & 5,456 & $\begin{array}{l}0 \\
00\end{array}$ & & \\
\hline $\begin{array}{c}\text { LA } \\
\text { BEL } \\
\text { HA } \\
\text { LA } \\
\text { L }\end{array}$ & $\begin{array}{r}6 \\
1 \\
7\end{array}$ & ,066 & $\begin{array}{c}.71 \\
0\end{array}$ & 9,330 & $\begin{array}{l}0 \\
00\end{array}$ & .596 & 1,679 \\
\hline $\begin{array}{l}\text { PR } \\
\text { OM } \\
\text { OSI }\end{array}$ & $\begin{array}{l}0 \\
9 \\
2\end{array}$ & ,046 & $\begin{array}{l}.15 \\
2\end{array}$ & 1,993 & $\begin{array}{l}0 \\
49\end{array}$ & ,596 & 1,679 \\
\hline
\end{tabular}

Tabel 14. Uji Hipotesis ( $t$ )

a) Dependen variabel: KEPUTUSAN PEMBELIAN Sumber: data diolah oleh spss 20 (2021)

1) Uji Hipotesis 1

H1 Diketahui 0,00 $<0,05$ dan thitung 9,330 > ttabel 1,984, sehingga dapat disimpulkan bahwa H1 diterima yang berarti secara parsial terdapat pengaruh positif signifikan antara label halal terhadap keputusan pembelian

2) Uji Hipotesis 2

H2 diketahui 0,049<0,05 dan thitung 1,993 > ttabel 1,984, sehingga dapat disimpulkan bahwa H2 diterima yang berarti secara parsial terdapat pengaruh positif signifikan antara label halal terhadap keputusan pembelian.

\section{Uji Signifikan Simultan (Uji F)}

Uji F dilihat dari hasil pada tabel 15 menunjukan apabila signifikan penelitian $<0,05$ maka H0 ditolak serta Ha diterima sehingga bisa diambil kesimpulan bila simultan variabel independen memiliki pengaruh signifikan terhadap variabel dependen.

Tabel 15. Uji Hipotesis 3 (F)

\begin{tabular}{cccccc}
\hline Model & $\begin{array}{c}\text { Sum of } \\
\text { Squarnes }\end{array}$ & df & $\begin{array}{c}\text { Mean } \\
\text { Square }\end{array}$ & F & sig \\
\hline Regression & 703,840 & 2 & 351.920 & 96,234 &, $000^{\mathrm{b}}$ \\
\hline Residual & 354,720 & 97 & 3,657 & & \\
\hline Total & 1058,560 & 99 & & & \\
\hline
\end{tabular}

a. Dependent variabel: KEPUTUSAN PEMBELIAN

b. Predictors: (constant), PROMOSI, LABEL HALAL

Sumber:data diolah oleh SPSS 20 (2021)

\section{Uji F Hipotesis 3}

Pada data diatas diketahui bahwa nilai Sig, untuk pengaruh variabel $\mathrm{X}$ terhadap $\mathrm{Y}$ adalah sebesar 0,000 < 0,05 dan nilai fhitung 96,234 > 3,94. Oleh karena itu dapat disimpulkan terdapat pengaruh label halal dan promosi secara simultan terhadap keputusan pembelian.

\section{Uji Koefisien Determinasi}

Pada Tabel 16 menunjukan hasil dari Uji Koefisien Determinasi:

\begin{tabular}{cccccc}
\hline Model & $\mathrm{R}$ & $\mathrm{R}$ & Adjusted & Std. Error & Durbin- \\
Square & $\mathrm{R}$ Square & $\begin{array}{c}\text { of the } \\
\text { Estimate }\end{array}$ & Watson \\
& & & &
\end{tabular}

\begin{tabular}{llllll}
\hline 1 &, $815^{\mathrm{a}}$ &, 665 &, 658 & 1,912 & 1,792 \\
\hline
\end{tabular}

Tabel 16. Uji Koefisien Determinasi a. Predictors: (constant), PROMOSI, LABEL HALAL

b. Dependent variabel: KEPUTUSAN PEMBELIAN Sumber: data diolah oleh SPSS 20 (2021)

Pada data di atas menunjukan dipengaruhi nilai koefisien R-square sebesar 0.665 atau 66,5\% jadi bisa diambil kesimpulan besarnya pengaruh variabel label halal dan promosisecara simultan terhadap keputusan pembelian sebesar 0,665 (66,5\%). 


\section{Pembahasaan Penelitian}

1) Pengaruh Label Halal Mie Samyang Terhadap Keputusan Pembelian (H1)

Dalam penelitian ini label halal mempunyai pengaruh positif dan signifikan terhadap keputusan pembelian. Hal ini dibuktikan dengan nilai regresi label halal 0,710. Nilai $t_{\text {hitung }} 9,330>t_{\text {tabel }} 1,984$ dengan tingkat signifikansi 0,00 $<0,05$, Ha diterima sehingga menjadi tanda bahwa terdapat pengaruh positif signifikan variabel Label halal (X1) terhadap keputusan pembelian (Y) Mie Samyang Halal di Jakarta.Bila label halal sesuai dengan kepentingan konsumen untuk membeli, maka akan meningkatkan keputusan pembelian. Label halal ini penting untuk konsumen mengetahuinya, karena label halal termasuk dengan syariat agama oleh karena itu label halal dapat mempengaruhi keputusan pembelian Mie Samyang Halal.

Hasil dari penelitian ini mendukung penelitian sebelumnya yang dilakukan oleh (Alfian, 2017) yang menunjukan bahwa label halal, brand, dan harga mempengaruhi terhadap keputusan pembelian di kota Medan, (Yulianto, 2019) yang menyatakan bahwa persepsi "label halal dan citra merek mempengaruhi terhadap minat beli yang dilakukan secara survei online pada akun Instagram @safiindonesia, (Prastya \& Suryadi., 2020) yang menunjukan labelisasi halal dan citra merk korea mempengaruhi keputusan pembelian pada konsumen di kota Metro.

2) Pengaruh Promosi Mie Samyang Terhadap Keputusan Pembelian (H2)

Dalam penelitian ini promosi mempunyai pengaruh positif dan signifikan terhadap keputuan pembelian. Hal ini dibuktikan dengan nilai regresipromosi 0,52 . Nilai thitung $1,993>t_{\text {tabel }} 1,984$, dengan tingkat signifikansi 0,049<0,05, Ha diterima sehingga menjadi tanda yang berarti terdapat pengaruh positif dan signifikan variabel (X2) terhadap Keputusan Pembelian (Y) Mie Samyang Halal di Jakarta.Promosi merupakan strategi pemasaran yang dapat mempengaruhi minat beli. Dalam berpromosi mie samyang memberikan kesan yang unik dan menarik perhatian untuk dibeli. Disaat sedang lapar mie samyang ini disantap dan memberikan rasa dan tekstur dari mie samyang sendiri, kenyal dan berbeda dari mie yang lain oleh karena itu mie samyang memberikan dampak positif terhadap keputusan pembelian pembeli.

Hasil penelitian berbeda dengan penelitian sebelumnya yang dilakukan oleh (Oktavianingroem, 2019) yang menunjukan bahwa kualitas produk, promosi dan harga mempengaruhi terhadap keputusan konsumen PT NISSIN FOOD, (Ahidin \& Nurfianti, 2019) menunjukan bahwa harga dan label halal mempengaruhi hasil yang signifikan terhadap keputusan pembelian produk mie samyang impor kepada pelanggan indomaret di kota Bogor ,(Muizzudin. \& Kisti, Amelia, 2020) menunjukan bahwa sertifikasi halal, citra merek dan harga mempengaruhi terhadap keputusan pembelian minuman teh botol sosro.

3) Pengaruh Label Halal dan Promosi Mie Samyang Halal terhadap Keputusan Pembelian (H3)

Ditunjukan dari hasil uji $\mathrm{t}$ bahwa variabel label halal dan promosi secara bersamaan berpengaruh signifikan terhadap keputusan pembelian. Berdasarkan uji f dilihat diatas sebesar 96,234 >3,94. Dan nilai signifikansinya sebesar $0,00<0,05$. Yang berarti bahwa Label Halal dan Promosi berpengaruh secara bersamaan secara simultan terhadap Keputusan Pembelian.

\section{KESIMPULAN}

Menurut pembahasaan dan hasil analisis yang peneliti uraikan di atas mengenai analisis keputusan pembelian mie samyang halal di Jakarta, maka dapat diambil kesimpulan bahwa untuk meningkatkan keputusan pembelian mie samyang maka perusahan dapat meningkatkan promosi dan konsisten label halal yang sudah menempel pada kemasan. Untuk itu, label halal mempunyai pengaruh positif terhadap keputusan pembelian mie samyang. Dan untuk meningkatkan keputusan pembelian mie samyang maka perusahaan dapat meningkatkan promosi yang baik dengan media sosial, agar promosi memiliki pengaruh yang signifikan positif terhadap keputusan pembelian mie samyang. Untuk meningkatkan keputusan pembelian mie samyang maka perusahaan dapat 
meningkatkan label halal yang sesuai syariat islam dan promosi yang baik yang dilakukan oleh media sosial, agar label halal dan promosi berpengaruh signifikan secara bersama terhadap Keputusan Pembelian mie samyang. Dengan ini label halal dan promosi secara simultan memiliki pengaruh terhadap keputusan pembelian mie samyang, oleh karna itu promosi yang dilakukan dengan baik menambah minat pada keputusan pembelian mie samyang. Saran untuk peneliti selanjutnya, diharapkan dapat menambahkan variabel. Hal ini ditunjukan agar lebih bervariasi untuk mengetahui hubungan antara satu variabel dengan variabel lainnya untuk kesempurnaan penelitian kedepannya.

\section{DAFTAR PUSTAKA}

Agustin, H. (2019). Studi Kelayakan Bisnis Syariah. PT Raja Grafinopersada.

Ahidin, U., \& Nurfianti, N. (2019). Analysis of Decisions for Purchasing Imported Products in Mie Samyang through Halal Labels and Prices ( Empirical Study in Indomaret Customers in the City of Bogor ). International Journal of Innovative Science and Research Technology, 4(10), 647-655.

Aisyah, Y. (2021). Samyang Challenge, Coba Bikin Kreasi 3 Mi Samyang Terbaru. Https://Www.Kompas.Com/. https://www.kompas.com/food/read/2021/0 1/19/214206075/samyang-challenge-cobabikin-kreasi-3-mi-samyang-terbaru?page=all

Alfian, I. (2017). Analisis Pengaruh Label Halal, Brand dan Harga Terhadap Keputusan Pembelian di Kota Medan. At-Tawassuth, Vol.2, No., 127.

Amaliah, Murdiati, A. (2013). Panduan Penyiapan Pangan Sehat Untuk Semua. Prenada Media.

BPOM. (2020). Pedoman Label Pangan Olahan. Badan Pengawas Obat Dan Makanan RI.

Ghozali, I. (2012). Aplikasi Analisis Multivariate dengan Program IBM SPSS. Universitas Diponegoro.

Halim, C. (2013). Tip Praktis: Promosi Online untuk Berbagai Event. Elex Media Komputindo.
Kotler, P. \&, \& Keller, K. L. (2012). Manajemen Pemasaran. Erlangga.

Kotler, P., \& Armstrong, G. (2016). Principles of Marketing, Global Edition (16th ed.). Pearson Education Limited.

LPPOM, M. (2021). Miliki Sertifikat Halal, Samyang Green Ungguli Produk Mi Instan Impor. Www.Halalmui.Org. https://www.halalmui.org/mui14/main/deta il/miliki-sertifikat-halal-samyang-greenungguli-produk-mi-instan-impor

Muizzudin., \& Kisti, Amelia, S. (2020). Pengaruh Sertifikasi Halal, Citra Merek, Dan Harga Terhadap Keputusan Pembelian Minuman Teh Botol Sosro. Journal of Islamic Economics, Business and Finance, 10(2), 137-151.

Oktavianingroem, D. A. G. (2019). Pengaruh Kualitas Produk, Promosi Dan Harga Terhadap Keputusan Konsumen Pt Nissin Food. Jurnal Ilmu Dan ... http://jurnalmahasiswa.stiesia.ac.id/index.ph p/jirm/article/view/793

Perwitasari, A. S. (2021). Produsen Mie Sedaap optimistis target pertumbuhan tahun 2020 tercapai. Https://Industri.Kontan.Co.Id/. https://industri.kontan.co.id/news/produsenmie-sedaap-optimistis-target-pertumbuhantahun-2020-tercapai

Prastya, Y., \& Suryadi. (2020). Pengaruh Labelisasi Halal dan Citra Merk terhadap Keputusan Pembelian Produk Mie Korea pada Konsumen di Kota Metro. Jurnal Manajemen Diversifikasi, 1(1), 1-11.

Pulungan, Hindun, M., Dewi, Atsari, I., Rahmah, Lailatul, N., Perdani, Gadizza, C., Wardina, K., \& Pujiana, D. (2018). Teknologi Pengemasan dan Penyimpanan. UB Press.

Purba, N. putri. (2021). Kasus Akibat Sering Mengkonsumsi Mie Instan. Https://Www.Kompasiana.Com/. https://www.kompasiana.com/nanda12519/6 0343f8e8ede4841bb3e1ad4/kasus-akibat-seringmengkonsumsi-mie-instan 
Rahayu, Martha, E. . (2017). Mie Samyang Resmi Kantongi Sertifikat Halal LPPOM MUI. Www.Kumparan.Com.

https://kumparan.com/swaonline/miesamyang-resmi-kantongi-sertifikat-halallppom-mui/full

Rangkuti, F. (2013). Strategi Promosi yang Kreatif dan Analisis Kasus. Gramedia Pustaka Utama.

Riyanto., S., \& Hatmawan., A. A. (2020). Metode Riset Penelitian Kuantitatif Penelitian Di Bidang Manajemen, Teknik, Pendidikan, Dan Eksperimen.

Sugiyono. (2014). Metode Penelitian Pendidikan Pendekatan Kuantitatif, Kualitatif dan RED. Alfabeta.

Sugiyono. (2015). Metode Penelitian Kombinasi (Mix Methods). Alfabeta.
Suteja, J. (2021). Samyang Perkenalkan Saus Buldak dan 3 Varian $\mathrm{Mi}$ Instan. Https://Www.Beritasatu.Com/. https://www.beritasatu.com/gayahidup/731387/samyang-perkenalkan-sausbuldak-dan-3-varian-mi-instan

Tjiptono, F. (2016). Strategi pemasaran. Andi Offset.

Yetti, F., \& Priyatno, P. D. (2021). Literasi Gerakan Gaya Hidup Halal Di Pondok Pesantren Al Jadid Kecamatan Kopo, Kabupaten Serang, Banten. Jurnal Pengabdian Kepada Masyarakat, 2, 2.

Yulianto, E. (2019). Minat Beli (Survei Online Pada Pengikut Akun Instagram @safiindonesia). Jurnal Administrasi Bisnis (JAB), 77(1). 